\title{
Recurrent Respiratory Papillomatosis
}

\author{
Naren N. Venkatesan, MD, Harold S. Pine, MD, and Michael P. Underbrink, MD \\ Department of Otolaryngology, University of Texas Medical Branch, 7.104 John Sealy Annex, 301 \\ University Boulevard, Galveston, TX 77555-0521, USA
}

\section{Keywords}

Papillomas; Papillomatosis; Aerodigestive tract; Human papillomavirus

RRP is the term used to describe infection of the upper aerodigestive tract by human papilloma virus (HPV). Although papillomas may present anywhere along the tract, the larynx is the most common location. ${ }^{1,2}$ RRP typically presents in a bimodal pattern during either adult life or early childhood. The latter presentation is marked by a more aggressive and recurring course, and therefore is commonly referred to separately as juvenile RRP. Because of this unpredictable course, knowledge and management of RRP is essential to any otolaryngology practice.

\section{INCIDENCE OF RRP}

Transmission of juvenile RRP occurs from the mother to the child either in utero or at the time of birth. The increase in prevalence of HPV cervical infections in women has been mimicked by an increase in RRP. Although it is difficult to ascertain the incidence of RRP, it is estimated that juvenile RRP is present in 4.3 per 100,000 people in the United States. ${ }^{3}$ As discussed later, the incidence of RRP has been greater in patients of lower socioeconomic status, another fact correlating with the increased incidence of HPV in this population. This belief was recently validated further by a pilot study of a large database of publically and privately insured patients in the United States. The study showed that the RRP incidence was higher in publically insured patients compared with privately insured patients by more than $150 \%: 3.21$ versus 1.98 per 100,000 , respectively. ${ }^{4}$

The Hospital for Sick Children in Toronto showed that nearly half of juvenile patients with RRP were below the poverty line for Canadian citizens. ${ }^{5}$ This finding further reinforces the idea that patients of lower socioeconomic status are at increased risk. However, no correlation has been found between socioeconomic status and severity of the disease. ${ }^{5}$

\section{ECONOMIC EFFECTS OF RRP}

Currently, there is no cure for RRP and so treatment is directed at preventing upper airway compromise and improving vocal function while preserving laryngeal tissues. Because of the infectious and proliferative nature of RRP disease, affected patients are prone to frequent recurrences and multiple surgical treatments. This disease not only affects individual patients significantly but also places a large economic burden on their families and society in general. Typical pediatric patients require nearly 20 surgical procedures throughout their lifetimes, many of which occur early in the children's lives. During the initial years of the

(C) 2012 Elsevier Inc. All rights reserved.

*Corresponding author: mpunderb@utmb.edu. 
disease, a child is estimated to require slightly more than 4 surgeries per year. ${ }^{6}$ Nearly $19 \%$ of children manifest a more aggressive course of the disease, requiring greater than 40 procedures in their lifetimes. ${ }^{7}$ The average lifetime cost to treat 1 patient with RRP has been estimated at $\$ 60,000$ to $\$ 470,000$ in the United States. ${ }^{4}$ On a national level, it is estimated that there are 15,000 surgical procedures performed every year in adults and children with RRP, with a total health care cost of nearly $\$ 150$ million. $^{3}$

\section{RESEARCH INTO RRP}

Although certain aspects of RRP continue to remain enigmatic, the disease's morbidity and significant economic burden are well established and underscore its clinical relevance. With any disease, some fundamental information regarding the epidemiology and virology provides a baseline for understanding. As a complex pathogen, the complete picture of the molecular mechanism of disease is still unclear; however, this aspect remains a key area of current research. Further, as a disease whose prevalence is growing, the transmission process as well as the role of recently introduced HPV vaccines is discussed. In addition, clinical manifestations and management of these patients continues to evolve with the advancement of new surgical technology and pharmaceutics.

\section{Causes/Epidemiology of RRP}

Through demonstration of papillomata on his arm, Ullman ${ }^{8}$ first confirmed the presence of an infectious agent in laryngeal papillomas in 1923. RRP was then confirmed to contain HPV DNA in 1980. Further characterization and typing was done by Gissman and colleagues ${ }^{9}$ and Mounts and colleagues, ${ }^{10}$ which confirmed the hypothesized role of HPV.

HPV is an icosahedral DNA capsid virus that is categorized based on genetic homology into greater than 180 identified genotypes, which correspond with different tissue preferences and clinical manifestations. HPV types 6 and 11 account for most cases of RRP. HPV-11 occurs most commonly (50\%-100\% of isolates $)^{9-14}$ and runs the most aggressive clinical course, followed by HPV-6. HPV types 16, 18, 31, and 33 have also been reported in RRP, albeit rarely. ${ }^{15}$

HPV types affecting the mucosal tracts can be broadly divided into high-risk and low-risk types based on their ability to cause malignant transformation of epithelial cells. High-risk types HPV-16 and HPV-18 are most commonly associated with cervical cancers as well as a subset of oropharyngeal carcinomas. HPV-6 and HPV-11 are considered low-risk types, not typically associated with malignancy, although transformation in RRP has been described. The rate of malignant transformation in RRP is less than $1 \%,{ }^{16}$ and has generally been reported in adults with other risk factors such as tobacco use or exposure to radiation but also in children with prolonged, extensive disease and distal spread. ${ }^{17-19}$ The cause of transformation is thought by some investigators to follow a gradual molecular transformation. In one example, this involved integration of HPV-11 DNA into the host genome in malignant tissue samples and mutation of the p53 proto-oncogene. ${ }^{18,20}$

In their largest series of 9 patients, Reidy and colleagues ${ }^{20}$ found HPV-11 to be present in all evaluable malignant samples, and RNA assays showed evidence of HPV integration in 3 of 7 sufficient samples. No evaluation of p53 status was performed in this study. In 5 sufficient samples from 7 patients with malignant transformation, Go and colleagues ${ }^{21}$ agreed with the consistent expression of HPV-11 in malignancy, and found p53 expression to be variable, but was not able to show a progressive histologic appearance in serial samples. The palliative treatment for benign RRP is redirected when malignant transformation occurs, using conventional head and neck cancer oncological principles that supersede the original "tissue sparing" goals. Most squamous cell carcinomas (SCCA) 
arising with a history of RRP are well differentiated, and, when occurring in the lung, seem to have a refractory course.

The question has also been raised regarding the presence of HPV in the clinically diseasefree larynx and respiratory tree. ${ }^{17}$ Although ethical concerns make it difficult to explore this area in disease-free human subjects, a meta-analysis has shown that up to $10 \%$ of normalappearing oral mucosa contained high-risk HPV. ${ }^{22}$ Furthermore, normal-appearing adjacent mucosa or areas appearing to be well treated may show dormant HPV when tested for HPV DNA rather than for histologic changes, as shown by the finding of HPV DNA in macroscopically normal sites in patients with RRP at a rate of $61 \% .{ }^{23}$ This latent HPV DNA may then become reactivated and cause recurrence of papillomas. As with other viral pathogens, stress on the patient's immune system may also serve as the trigger for the virus replication. One recent study showed that children with RRP have reduced CD 4/CD 8 ratios and poor lymphocyte response to mitogen stimulation, implying that these children have inadequate cell-mediated immunity. ${ }^{24}$ Thus, a deficient host immune system is likely another factor in the development of recurrent disease.

\section{HPV Virology}

The HPV is an icosahedral capsid DNA virus in the family Papovaviridae. It contains no envelope and has a double-stranded DNA genome containing approximately 8000 base pairs. HPV has a propensity for infecting epithelial cells. Although only select types are associated with RRP, more than 100 types of HPV have been identified, varying in the species they infect and the epithelial tissue they prefer. HPV infects stem cells within the basal layer of mucosa.

HPV genome-The HPV genome consists of 8 genes coding for E1, E2, E4, E5, E6, E7, $\mathrm{L} 1$, and $\mathrm{L} 2$. The $\mathrm{L} 1$ and $\mathrm{L} 2$ proteins are transcribed late in the viral life cycle and are responsible for producing the viral capsid. The E designation refers to genes that are transcribed early in the viral life cycle and are responsible for replication of the viral genome using host cellular machinery. These early genes also encode for potent oncoproteins that interact with many host cellular proteins and can cause transforming activities and disrupt cell growth and function. The most studied of these are the E6 and E7 proteins, which have been shown to prevent apoptosis and alter cell cycle function. They target the p53 and retinoblastoma tumor suppressor proteins, respectively. The tumor suppressor, p53, is an important cellular protein serving the important cellular functions of sensing and stimulating the repair of damaged DNA and triggering apoptosis of severely compromised cells.

The retinoblastoma tumor suppressor $(\mathrm{pRb})$ and related pocket proteins, $\mathrm{p} 107$ and $\mathrm{p} 130$, are important regulatory subunits of the E2F transcription family members, which control cellular differentiation and proliferation. ${ }^{25}$ The ability of E6 and E7 to disrupt the functions of $\mathrm{p} 53$ and $\mathrm{pRb}$, respectively, is thus necessary for promoting proliferation and uncoupling differentiation. These cellular interactions, in turn, are able to keep the differentiating keratinocytes in a DNA replicative state, which is essential for progression of the HPV life cycle. However, these same processes can lead to transformation of the cell when left unregulated, such as occurs after the physical integration of high-risk HPV viral genomes into a host chromosome.

In high-risk HPVs, the E6 protein complexes with the E3 ubiquitin ligase, E6AP, and targets the p53 protein for ubiquitin-mediated proteosomal degradation. ${ }^{17}$ It is the level of p53 breakdown that correlates with transformation risk. Both high-risk and low-risk E6 are able to bind 553 , although only high-risk E6 proteins promote its degradation. ${ }^{26}$ This functional difference between high-risk and low-risk E6 is explained by the binding of these proteins to different regions within p53. ${ }^{27}$ Both high-risk and low-risk E6 proteins interact with the C- 
terminal domain of p53, but only high-risk E6 contacts the p53 core domain, an interaction that likely mediates the degradation of p53. ${ }^{28}$ The high-risk E7 protein binds the retinoblastoma family of proteins (pRb, p107, and p130) and also induces their proteolytic degradation, which in turn allows for cell immortalization and helps to overcome DNA damage arrest signals. ${ }^{29}$ Thus, cells expressing E7 are able to enter $\mathrm{S}$ phase in the absence of growth factors and despite the presence of inhibitory signals. High-risk E7 proteins have a greater transformation potential than low-risk E7 proteins, which correlates with the higher binding affinity of the high-risk E7 proteins for $\mathrm{pRb}$. $^{25,30}$

HPV histology-Histologically, HPV appears as a pedunculated mass with fingerlike projections or multiple fronds with a central fibrovascular core covered by stratified squamous epithelium. ${ }^{31}$ The laryngeal mucosa appears velvety when papillomas remain microscopic, which is in contrast with the typical pinkish-whitish cauliflower presentation seen in the exophytic form. HPV also leads to a delay in epithelial maturation resulting in basal layer thickening and increased presence of nucleated cells in the suprabasal layer of the stratified epithelium. ${ }^{32}$

\section{Molecular Mechanisms of RRP Disease}

Although there are limited studies dealing with the molecular pathophysiology of the HPV types involved in RRP, there is a wealth of epidemiologic and molecular data on high-risk HPV types implicated as causing cervical cancers and a subset of head and neck cancers. ${ }^{33,34}$ Cervical carcinomas harbor integrated high-risk HPV genomes within each tumor cell and continue to express the E6 and E7 viral oncogenes. As previously discussed, the high-risk E6 and E7 proteins modify the expression patterns and activities of many cellular genes and proteins to promote cell proliferation. It has been shown that both the E6 and E7 high-risk proteins are necessary for efficient immortalization of human keratinocytes. $^{25}$

At the molecular level, much is known about the E6 and E7 oncoproteins of the high-risk HPVs, as discussed previously. In addition to binding the retinoblastoma family of proteins (pRb, p107, and p130) and targeting them for degradation, high-risk E7 is able to bind histone deacetylase (HDAC). Together, these activities allow cell immortalization and help to overcome DNA damage arrest signals. ${ }^{29,35,36}$ High-risk HPV E7-expressing cells have also been shown to stabilize and increase the half-life of p53, ${ }^{37,38}$ either by disrupting the p53-specific ubiquitin ligase $\mathrm{mdm} 2^{39}$ or by E2F-mediated transcriptional induction of p14ARF. ${ }^{40}$ Furthermore, high-risk E7 is able to abrogate the cytostatic activities of certain cytokines important for restricting cellular growth and mounting an immune response to viral infection, such as transforming growth factor $\beta$ (TGF- $\beta$ ), tumor necrosis factor $\alpha$ (TNF- $a$ ), IFN- $a$ and IFN- $\gamma$, and insulin-like growth factors (IGFs). TGF- $\beta$, which is important for restricting epithelial cell growth, is resisted by high-risk E7 expression ${ }^{41}$ and occurs in parallel with the acquisition of resistance to differentiation cues in E7-expressing keratinocytes. ${ }^{42}$ TNF- $\beta$, an important mediator of immune response produced by cytotoxic T cells, also induces G1 growth arrest and cellular differentiation in normal keratinocytes. HPV E7-expressing keratinocytes continue to proliferate in the presence of TNF- $\beta .{ }^{43}$ IFNs are produced in response to viral infections. HPV E7 can subvert the cellular response to IFNs by disrupting either IFN-a-mediated cellular signaling 44 or by downregulating the expression of IFN- $\beta .^{45-47}$ In addition, E7 can interact with insulinlike growth factor-binding protein- $3,{ }^{48}$ and thus control the cellular availability of IGFs.

In addition to targeting p53 for degradation, high-risk E6 possesses redundant mechanisms for inactivating p53 and apoptosis. High-risk E6 can bind to p300, which blocks p53 acetylation and inhibits its ability to transactivate gene expression. ${ }^{49}$ Also, E6 proteins target 
the proapoptotic effector, Bak, for proteolytic degradation, ${ }^{50,51}$ thus inhibiting the intrinsic apoptosis pathway. High-risk E6 is also capable of inhibiting the extrinsic apoptosis pathway stimulated by both the Fas and the TNF-related apoptosis-inducing ligand (TRAIL) pathways. This inhibition is mediated by E6 binding to, and degradation of, both the Fasassociated protein with death domain (FADD) adapter protein and the effector caspase, caspase- $8 .{ }^{52}$ Furthermore, it has been observed that cells expressing the high-risk E6 proteins display a reduced ability to repair DNA damage. ${ }^{53,54}$ Because the repair of DNA damage depends, at least in part, on the p53 status of cell, this may be caused by these E6expressing cells being functionally $\mathrm{p} 53$ null. ${ }^{55}$ Despite the inability to degrade $\mathrm{p} 53$, the E6 protein from a range of cutaneous HPV types effectively inhibits apoptosis in response to genotoxic ultraviolet (UV) damage. ${ }^{56}$ This may partially be explained by the ability of E6 proteins to attenuate the UV-induced transactivation of p53-regulated proapoptotic genes Fas, PUMA, Apaf-1, and PIG3 ${ }^{57}$ Further evidence of the ability of high-risk E6 to abrogate p53 function is by activating the transcription of $\triangle \mathrm{NP73}$, an isoform of the p53-related protein $\mathrm{p} 73$, which in turn inhibits the capacity of p53 to induce the transcription of genes involved in growth suppression and apoptosis. ${ }^{58}$ In addition, high-risk E6 is able to induce telomerase activity in keratinocytes, which does not rely on p53 interaction but does require E6AP and is important for extending the life span of infected cells and their subsequent immortalization. 59,60

By comparison, low-risk E6 and E7 proteins are usually included in molecular studies of high-risk HPV types because of their general lack of such abilities. For example, the E6 and E7 proteins of low-risk HPVs do not seem to express cell-transforming activities that are comparable with those of their high-risk counterparts. ${ }^{30,61}$ It is also well known that the ability to promote the degradation of p53 is restricted to high-risk HPV types. ${ }^{62}$ In addition, low-risk E7 binds to $\mathrm{pRb}$ family members with lower affinity than high-risk E ${ }^{25}$ and does not target $\mathrm{pRb}$ for degradation. ${ }^{63}$ Despite these differences in function, the low-risk E6 and E7 proteins share significant homology with the high-risk proteins ${ }^{64,65}$ and retain many of the same abilities that provide redundant mechanisms for promoting cellular proliferation, disrupting apoptosis, and uncoupling cellular differentiation.

Conserved E6 functions-Both HPV-16 and HPV-11 E6 proteins bind TRIP-Br1 (transcriptional integrator of the E2F1/DP1/RB cell cycle regulatory pathway). TRIP-Br1 modulates transcription of genes relevant for G1/S transition in the same direction as the E7 protein, through disruption of E2F1 transcriptional regulation. This redundancy in function shows important similarities between high-risk and low-risk E6 proteins that are important for both the HPV life cycle and potential cellular transformation. ${ }^{66}$ In addition, high-risk and low-risk E6 proteins from HPV-16, HPV-18, and HPV-11 destabilize TIP60 (Tat-interacting protein $60 \mathrm{kDa}$ ), which relieves cellular promoters from TIP60 repression and abrogates p53-dependent activation of the apoptotic pathway. Degradation of TIP60, therefore, allows low-risk and high-risk HPVs to promote cell proliferation and cell survival. ${ }^{67}$ Furthermore, HPV-16 and HPV-11 E6 proteins also bind and inactivate p73, which, at the least, promotes cell growth and may contribute to cellular transformation. ${ }^{68}$ In addition, the ability to degrade the proapoptotic Bcl-2 family member, Bak, is conserved in high-risk and low-risk E6-expressing cells. ${ }^{55,69}$ This ability to circumvent apoptosis is important for the HPV life cycle and presumably its transformation potential.

Conserved E7 functions-HPV-6, HPV-16, and HPV-18 E7 proteins interact with PCAF (P300/calcium-binding protein-associated factor) acetyltransferase, which is a coactivator for a variety of transcription factors including $\mathrm{p} 53,{ }^{70}$ and thereby contributes to altered cellular gene expression and growth. Also, the E7 proteins from both high-risk and low-risk HPV types 16 and 11 interact with p300 and abolish p300-mediated E2 transactivation, which is important for differentiation-dependent activation of viral gene 
expression and potential cellular transformation. ${ }^{71}$ In addition, both high-risk and low-risk E7 proteins $(16,18,31$, and 11) bind hypoxia-inducible factor 1a (HIF-1a) and enhance HIF-1a activity via displacement of HDACs. This mechanism is important for promoting epithelial growth through activation of angiogenesis. Furthermore, introduction of either high-risk or low-risk E7 genes (18 and 6) into epithelial raft cultures induces proliferating cell nuclear antigen (PCNA) expression in suprabasal cells, which indicates the importance of the E7 protein in reactivating host DNA replication machinery in differentiated, noncycling cells. ${ }^{72}$ In addition, HPV-6 E7, like HPV-16 E7, interacts with and decreases the levels of p130, despite being unable to degrade other retinoblastoma tumor suppressor protein family members ( $\mathrm{pRb}$ and $\mathrm{p} 107$ ). The ability of E7 proteins to destabilize the $\mathrm{pRb}$ family members depends on cellular differentiation, because both high-risk and low-risk E7 destabilize p130 in either differentiated or undifferentiated growth conditions. Only highrisk 16E7 degrades $\mathrm{pRb}$ in both growth conditions, whereas p107 is only destabilized by $16 \mathrm{E} 7$ in undifferentiated conditions. ${ }^{73}$ The degradation of p130 is therefore likely necessary to complete the virus life cycle, whereas the added ability of $16 \mathrm{E} 7$ to regulate $\mathrm{pRb}$ and p107 may be related to oncogenic activity.

Immune responses-Another area of molecular interest is the complex innate and adaptive immune responses made by the host with respect to HPV-6 and HPV-11 infection. It remains unclear why only a small fraction of HPV-exposed individuals develop RRP, and why still fewer develop a severe course of the disease. One explanation proposes that patients with RRP are unable to produce an effective HPV-specific T-cell response, as shown by an altered $\mathrm{CD}^{+}$subset and the $\mathrm{T}_{\mathrm{H}} 1 / \mathrm{T}_{\mathrm{H}} 2$ cytokine imbalance found in these patients. ${ }^{74}$ Supportive evidence for this theory later came from comparing relative gene expression levels between papilloma and adjacent normal tissue with respect to immune responsive genes using microarray analysis. ${ }^{75}$ Additional studies revealed that HPV-11 E6 skews IL-10 and IFN- $\gamma$ expression by patients with RRP toward increased IL-10 expression $\left(\mathrm{T}_{\mathrm{H}} 2\right)$ and away from IFN- $\gamma\left(\mathrm{T}_{\mathrm{H}} 1\right)$, which may be explained by an E6-induced dendritic cell dysfunction in these patients that shifts their HPV-specific immune responses toward IL-10 expression. ${ }^{76}$ Further evidence of a dysfunctional immune response by patients with RRP is the finding that the transporter associated with antigen presentation (TAP-1) is downregulated along with the major histocompatibility complex (MHC) class I antigen in benign papillomas. TAP-1 protein expression correlated inversely with the frequency of disease recurrence. These findings suggest that HPV may evade immune recognition by decreasing the MHC cell surface expression via downregulation of TAP- $1 .{ }^{77}$

\section{Transmission of HPV}

HPV is considered to be the most common sexually transmitted infection in the United States. ${ }^{78} \mathrm{HPV}$ prevalence has been gradually increasing in the female population. It is estimated that the overall prevalence of HPV in women aged 14 to 59 years is $26.8 \%$. When analyzing smaller age groups, there is a prevalence of nearly $45 \%$ in women between the ages of 20 and 24 years. ${ }^{79}$ These numbers also increase when factors such as education, poverty index, and marital status are taken into consideration. The prevalence increases in lower socioeconomic individuals, especially when they are unmarried and have not completed high school. ${ }^{79}$ In addition, one study showed that the prevalence of HPV-6 or HPV-11 in sexually active women from 18 to 25 years of age was $2.2 \%$, whereas the prevalence of HPV-16 or HPV-18 in the same cohort was $7.8 \% .{ }^{80}$

Mother-to-child HPV transmission-Being a sexually transmitted disease, it has been hypothesized that HPV is transmitted vertically from the mother to the neonate during passage through the birth canal. However, this method has not been shown conclusively as the only mechanism for HPV infection. It has been shown that children born to mothers with 
active condylomata have an increased risk of infection, as much as 231 times that of diseasefree mothers. ${ }^{81}$ Additional risk of infection occurs when affected primigravid mothers have prolonged vaginal deliveries, especially with an increased duration after rupture of the membrane. Such an occurrence is thought to cause further risk because the neonate spends a greater amount of time exposed to the virus. The same study showed that the risk increased to nearly double if labor lasted for greater than 10 hours. It has also been suggested that newly acquired HPV infections tend to have greater infectivity compared with chronic infections. ${ }^{82}$ These 2 factors alone show why low socioeconomic status (a group that has an increased prevalence of HPV) and age of the mother (increased likelihood of new-onset HPV and prolonged labor) are key risk factors for a neonate to develop RRP.

Although this knowledge helps to show the correlation between children with RRP and mothers with HPV, it implies a higher prevalence of this disease in children. However, despite how common HPV infections and active condylomata are in child-bearing women, RRP is an uncommon disease entity. Further, the odds of a child contracting HPV from a mother with active condylomata have been estimated at around 1 in $400,{ }^{83}$ which again suggests additional risk factors. Therefore, other factors seem likely to be important in the development of RRP: patient immunity; timing, length, and volume of virus exposure; and local traumas (intubation, extra-esophageal reflux). ${ }^{7}$ In addition, neonates may become infected before birth, as evidenced by a recent study showing that approximately $12 \%$ of neonates may develop HPV infections through transplacental transmission. ${ }^{84}$

Caesarean section for HPV transmittal prevention-The hypothesis that HPV is transmitted to the neonate during transit through the birth canal has raised the question of whether caesarean section (C-section) may provide some degree of protection against transmission of HPV. A recent systematic review of literature was undertaken to answer this question. ${ }^{85}$ The investigators showed that there was no statistically significant difference between the rates of HPV transmission from HPV-positive mothers either through vaginal delivery or C-section. Of the 6 selected studies, $3^{86-88}$ showed no difference, whereas 3 studies ${ }^{89-91}$ did show a decrease in HPV transmission with C-section. Tseng and colleagues ${ }^{90}$ only included women with an intact amniotic sac before undergoing surgery in the C-section group. All women with rupture of membranes before $\mathrm{C}$-section were excluded because these neonates may have been exposed to the virus in the window period between rupture of the amniotic sac and time of C-section. With these criteria for the C-section group, their results still showed a significant increase in HPV transmission with vaginal delivery compared with $\mathrm{C}$-section, with a number needed to treat of only 5 . The findings in this study correlate with other data ${ }^{91}$ showing that membrane rupture even 2 hours before delivery (vaginal or C-section) increases the risk of HPV transmission.

Because prolonged exposure to HPV following rupture of the membrane can be bypassed through a C-section, it is possible that the difference between transmission rates among each type of delivery may increase when this aspect is considered. Although a planned C-section is a routine procedure, it still carries inherent surgical risks and results in increased morbidity and mortality for the mother. ${ }^{7}$ Further studies are needed to determine the benefit of a planned C-section in an HPV-positive pregnant woman; however, it is a topic worthy of discussion between an at-risk mother and her birth care provider.

HPV vaccine-The recent advent of the HPV vaccine is encouraging, in that it will undoubtedly affect the spread of this disease. There are currently 2 vaccines present on the market. Cer-varix, a European-approved product of Glaxo-Smith-Kline, is a bivalent vaccine designed against the L1 capsid proteins of HPV-16 and HPV-18, the 2 most common causes of cervical cancer. However, although vaccination against HPV-16 and HPV-18 may help prevent cervical cancer, this vaccine does not address HPV-6 and HPV-11, the most 
common causes of RRP. Gardasil is a prophylactic quadrivalent vaccine with activity against HPV-6, HPV-11, HPV-16, and HPV-18. It includes recombinant virus-like particles designed from the L1 capsid protein of the 4 different HPV types. A product of Merck, it was implemented on June 8, 2006, by the US Food and Drug Administration following the findings in the phase III study and several phase II studies that prompted the Advisory Committee on Immunization Practices (ACIP) to recommend its use. ${ }^{92}$ Further, it was recommended that all girls 11 to 12 years old, and even as young as 9 years old, be given the vaccine along with women aged 13 to 26 years. ${ }^{93}$

Although there has been a growing negative response from parents toward vaccination because of the social stigma of the disease, HPV vaccination provides an overwhelming benefit for high-risk individuals. More importantly, preventative vaccination must be administered before sexual debut regardless of age, which further raises parental concerns. About $13 \%$ of American girls are sexually experienced by 15 years, and this number increases to $43 \%$ by age 17 years and $70 \%$ by age 19 years. ${ }^{94}$ Also, the increase of teenage pregnancy compounds the problem of potential neonatal transmission of HPV. So although the concept of preventative vaccination of HPV seems straightforward from a medical perspective, the underlying social issues are problematic.

In addition, the vaccine has also been approved for treatment in men. The idea of vaccinating boys has been embraced by other countries, such as Australia, where it is available to boys from the age of 9 to 15 years. ${ }^{95} \mathrm{HPV}$ infection among men seems to be as common as in women but is often a symptomatic, which contributes to the high rate of transmission between sexual partners. ${ }^{96}$ Because of its silent presentation, HPV transmission during heterosexual contact can occur without either partner being aware. The proponents of administering the vaccine to boys hope that the vaccination of both girls and boys will help slow the spread of the major serotypes of HPV.

Although each individual benefits from vaccination, it is uncertain what effect this will have on neonatal transmission of HPV or on the overall incidence of RRP. For an individual neonate, there may be an added benefit from vaccination in conjunction with performing Csection before rupture of the amniotic sac. It has been suggested that vaccines might eventually be useful in neonates for 2 reasons: (1) via transmission of immunity through maternal antibodies, and (2) through direct vaccination of neonates similar to hepatitis B neonatal vaccination. ${ }^{97}$ Currently, HPV vaccines are not approved for routine use on neonates, so this application requires further research.

The concept of herd immunity through vaccination of at-risk individuals should also be considered. The basis of this belief is that all women, and likely all men, from a specific age group within the population will be vaccinated. The number of those vaccinated eventually overwhelms those who are infected. As subsequent generations continue to be vaccinated, those vaccinated individuals will theoretically provide the community with immunity against the disease. Ideally, once such a community status exists, there will also be a consequent decrease in incidence of disease, in this case RRP. With these theories in mind, the HPV vaccine promises to decrease the future incidence of RRP; however, this needs further testing.

\section{Clinical Manifestations of RRP}

General respiratory symptoms in RRP-Despite becoming infected either before or during birth, most pediatric patients do not manifest any symptoms of RRP immediately. The larynx is the most common site of infection in children and, therefore, presenting symptoms tend to reflect this fact. As expected with laryngeal involvement, hoarseness is the first symptom noted; however, because of the subtle nature of this finding in a child, 
much less an infant, clinical suspicion for a disease process rarely arises. ${ }^{98}$ Other symptoms, secondary to upper airway involvement, may include dyspnea, chronic cough, recurrent upper respiratory infections, pneumonia, acute respiratory distress, dysphagia, and/or failure to thrive. ${ }^{2}$ Stridor, initially inspiratory and then biphasic, can be the presenting symptom of RRP and warrants significant clinical suspicion for disease and the appropriate work-up, including examination of the larynx and upper airway.

Delay in diagnosing RRP-Without a reason to suspect RRP, many patients are initially assumed to have a more common respiratory problem, such as croup, asthma, or bronchitis. Depending on the age of the child and based on the symptoms discussed earlier, allergies, acid reflux, and/or vocal fold nodules are often included in the differential diagnosis and worked up appropriately. Because of a low index of suspicion and subtle presenting signs, the definitive diagnosis of RRP is often made around 1 year after initial symptoms began. ${ }^{3,99} \mathrm{RRP}$ is most commonly diagnosed between 2 and 4 years of age, with dysphonia being the most common presenting complaint. ${ }^{100,101}$ Most juvenile patients with RRP $(75 \%)$ are diagnosed by age 5 years. ${ }^{7}$

Variable course of RRP-As a highly unpredictable disease, RRP can vary in course with each affected patient. In a percentage of patients, the disease is aggressive and requires frequent debridement to protect from airway compromise. In contrast, select patients may show a progressive and sometimes spontaneous remission. Although these 2 extremes are noted, most tend to exhibit a course that lies somewhere in the middle. The course of RRP in certain patients may be further affected by the introduction of a tracheotomy or endotracheal tube. Despite the benefits of providing a secure airway, irritation and disruption of normal mucosa by these tubes increases the risk of spreading papillomas into the subglottis and proximal trachea. Nearly $30 \%$ of affected children manifest extralaryngeal spread of RRP. ${ }^{102}$ The most common site is the oral cavity followed by trachea, bronchi, and then esophagus. $3,98,102$ In some rare cases, the larynx may be completely unaffected, despite the presence of tracheal disease. ${ }^{103}$

Pulmonary spread of RRP can be identified on computed tomography (CT) as non-calcified peripheral nodules that show central cavitation and air-fluid levels. Patients with pulmonary RRP incur perhaps the most aggressive course of the disease. Beginning initially with recurrent pneumonias and bronchiectasis, these patients eventually progress to frank pulmonary failure caused by destruction of underlying lung parenchyma as the disease progresses. In severe cases, malignant transformation of RRP into SCCA occurs. ${ }^{102}$ This typically fatal presentation is rare, accounting for less than $1 \%$ of disease presentations and is usually associated with HPV-11 infection. ${ }^{104,105}$ Figs. $1-4$ show varying presentations of RRP.

Pearls \& Pitfalls: Because of the risk of malignant conversion, it is necessary to take adequate biopsies periodically during subsequent procedures and monitor for any concerning pulmonary changes.

Staging of RRP is integral for both the clinician's knowledge of the progress of the disease as well as for clear communication of the patient's status to another physician. Although various staging schemes exist, they share certain principles. One of the more commonly used staging systems assigns numeric scores for a combination of subjective and objective findings. ${ }^{106,107}$ In the subjective portion, the patient's level of respiratory distress, stridor, urgency of intervention, and voice are qualified. In addition, an aspect of a surgical timeframe may be included by charting the time between surgeries and number of surgeries in a specific time period. The second half of the assessment is a quantification of the disease through the use of laryngoscopy. It entails assessing the extent of the lesion (small surface lesion to large bulky lesion) and the locations of the lesions. Typically, the locations are 
separated according to subsites within the larynx, subsites in the trachea, and an extra category for presence of lesions elsewhere. The most important aspect of staging is including an extensive level of detail when recording the objective laryngoscopic findings. Once staged, the need for treatment can be assessed and the evaluation of the prior intervention can be determined. This information is particularly useful when adjuvant therapy is being used, and benefits of the medications need to be balanced against potential toxicities (Fig. 5).

Pearls \& Pitfalls: Implementation of a staging system allows for the practitioner to make an accurate comparison of the patient's disease between visits and to clearly communicate the disease severity with other physicians.

\section{Treatment of Recurrent Respiratory Papilloma}

The treatment of RRP largely consists of surgical management, often augmented by the use of pharmacotherapy. Surgical treatment consists of debulking the papillomas to secure a stable airway while preserving the underlying laryngeal tissues. Surgery is often performed via microscopic or endoscopic rigid laryngoscopy in the operating room using either a laser or microdebrider to remove papillomas. A variety of lasers have been used for this purpose, including CO2, KTP (potassium titanyl phosphate), and pulse-dyed lasers. Although lasers remain the traditional standard, the use of microdebriders has been gaining favor. The reason for this trend is the ability of the microdebrider to selectively suction the affected tissue, which often allows for more precise debridement, limited damage to the underlying tissues, and greater preservation of normal epithelium. These characteristics become increasingly important because of the nature of RRP, which often necessitates several visits to the operating room for debulking, with an average of 4.1 to 4.4 surgeries during the first year of diagnosis alone. ${ }^{6}$ See Figs. 6 and 7 for preoperative and postoperative surgical intervention for laryngeal lesions and see Video 1 on the technique of microdebrider for removal of papillomas.

Pearls \& Pitfalls: With the specially designed blade for the microdebrider, lesions can be separated through use of suction from benign laryngeal tissue during resection, without need for cold dissection.

Surgical treatment of RRP-Among surgical options, a tracheotomy may be performed, but it is typically reserved for those most aggressive cases with impending airway compromise. Although this procedure may be necessary to secure an airway, it does provide another site for rapid colonization and serves as a conduit for disease spread to the tracheobronchial tree. ${ }^{1}$ In a series studying patients with RRP in whom a tracheotomy was performed, tracheal papillomas were present in more than half of those patients. ${ }^{108}$ Therefore, it is widely accepted now that tracheotomy should be reserved for only those cases in which multiple debulking surgeries have failed and/or the child's airway becomes compromised. Furthermore, if a tracheotomy is unavoidable, decannulation should be considered as early as possible once the disease process is controlled and the airway is deemed stable.

Adjuvant therapy for RRP-Adjuvant pharmacotherapy for the treatment of RRP continues to be an area of exploratory interest, with several agents currently used that work by varying mechanisms. One example is (IFN- $\alpha$, a human leukocyte protein produced by the body naturally in response to viral infections. Although its exact mechanism of action in RRP is not well understood, its natural role in the immune response is to bind cell receptors and modulate the cell's metabolism, leading to antiproliferative and immune-protective effects. The benefits of this therapy must also be weighed against the toxicities of IFN-a, which include thrombocytopenia and leukopenia. In addition, systemic symptoms, such as 
fevers, fatigue, nausea, arthralgia, and headache, make prolonged therapy difficult for the patient.

A recent multicenter study comparing surgery alone versus surgery with adjuvant IFN-a showed an initial decrease in disease progression at 6 months. ${ }^{109}$ However, this effect did not persist after 2 years, and no benefit was observed from the use of adjuvant IFN- $a$ rather than surgery alone. A different study showed that continuous use of IFN-a resulted in a response rate of $75 \%$ with a third of patients undergoing complete remission of their disease. The proposed algorithm by Leventhal and colleagues ${ }^{110}$ is to start with the use of IFN-a for 6 months then reevaluate the disease response. Prolonged use is encouraged if a positive response is noted; however, treatment should be halted if no response is noted or toxicities develop. An increased response to IFN-a in patients with HPV-6 compared with HPV-11 disease may also exist. ${ }^{111}$ Although its exact benefit is unpredictable, IFN-a remains a cornerstone in adjuvant therapy for RRP.

Among antiviral agents, cidofovir is the most used agent. Ribavirin has been used sparsely and has not shown any clear aid in disease suppression. ${ }^{112}$ Cidofovir, as an analogue of cytosine, has antiviral activity against DNA viruses. Its effects are induction of apoptosis and augmentation of the immune system, although the exact mechanism is not well understood. ${ }^{113}$ Cidofovir may be used either through traditional intralesional injections or, more recently, inhalation. ${ }^{114}$ Intralesional injections of cidofovir at the time of surgery have been tested in prospective studies that showed partial to complete regression of papillomas and a decrease in the frequency of debulking surgeries. ${ }^{115-121}$ A benefit of intralesional injections is that a higher concentration can be reached locally without greatly increasing plasma levels. ${ }^{121}$ Despite this advantage, the toxicities of intravenous use of cidofovir in humans should be considered, and include nephrotoxicity, bone marrow toxicity, iritis, and uveitis. ${ }^{122}$ Its off label use should be cautioned against because cidofovir has been found to be carcinogenic, embryotoxic, and teratogenic in animals. ${ }^{123}$ Despite these harmful effects, a review of literature discussing cidofovir as adjuvant therapy showed that greater $80 \%$ of patients show either partial or complete response. ${ }^{124}$ The caveat to these positive findings is that no statistically significant study has yet been performed comparing surgical debridement plus cidofovir with surgical debridement plus placebo.

Other recent agents include indole-3-carbinol (I3C), HSP E7, mumps vaccine, and photodynamic therapy (PDT). I3C is derived from cruciferous vegetables and has shown promise in vitro by decreasing papilloma growth through manipulation of estrogen metabolism. In a small clinical trial of 9 patients, 4 patients had partial or complete response with no negative effects. ${ }^{125}$ HSP E7 is a recombinant protein combining heat shock protein 65 of Mycobacterium bovis and the E7 protein of HPV-16. In a study of HSP E7 administered subcutaneously, a decrease in frequency of surgery and a decrease in the absolute number of surgical procedures were noted with mild reactions at the site of injection. ${ }^{126}$

Intralesional injections of the mumps vaccine has been tested and showed an increased length of remission in children, with low, if any, adverse effects. ${ }^{127}$ In this case series, the author outlined the use of mumps vaccine injected at the base of a lesion before use of a $\mathrm{CO}_{2}$ laser to remove the papillomas. Following a remission rate of greater than $80 \%$ in a small test group, a second, larger group was treated in a similar fashion with nearly identical results after a minimum of 2 years' follow-up. Despite this success, the study required a control group and a fixed algorithm to provide internal validity. The mumps vaccine has been used in cutaneous lesions to help generate a local inflammatory response, but this same principle has not been shown with RRP. Although this series reflects a pattern, the assumption of causality should not be made without a control. The use of intralesional 
mumps vaccine as an adjuvant therapy is an intriguing hypothesis, but it can only remain as such without a prospective, randomized trial to lend credence. ${ }^{128}$

Pearls \& Pitfalls: Although $\mathrm{CO}_{2}$ laser was initially favored, its longer wave-length causes greater thermal injury to underlying tissue. The newer angiolytic KTP and pulse-dyed lasers cause less thermal damage without disruption of the basement membrane.

PDT for RRP-Photodynamic therapy (PDT) in the treatment of RRP has shown promise. The benefit of this modality to selectively treat tumor cells without causing damage to healthy tissue makes this treatment unique. ${ }^{129,130}$ PDT has been approved for use in lung cancer, esophageal cancer, and Barrett esophagus. RRP shares a similarity with these disorders in that the area of disease is superficial and has high cell turnover. PDT is used in conjunction with an injectable photosensitizer, such as Photofrin ( $\mathrm{Pc} 4)$, which promotes apoptosis in cells after laser excitation. In the case of RRP, the PDT may provide benefit by altering the immune response, making it more sensitive to even low concentrations of viral proteins. ${ }^{131,132}$ Currently, there are some discrepancies concerning the benefit of PDT, with some studies showing decreased papilloma growth and potential long-term effects, whereas others show limited benefits. ${ }^{133-135}$ PDT remains an area of future study to better understand its mechanism of action as well as to evaluate its benefit as adjuvant therapy.

Laryngopharyngeal reflux treatment related to $\mathbf{R} \mathbf{R}-$ One additional area to mention in the treatment of RRP is the management of laryngopharyngeal reflux disease (LPRD). Irritation of the epithelium of the aerodigestive tract triggered by LPRD, either through acid or gastric enzyme interaction, may produce mucosal damage or an inflammatory response that could potentially trigger proliferation or spread of papilloma disease. Effective management of LPRD may result in improved control of RRP and possibly complete remission. ${ }^{135-137}$ In a small group of pediatric patients, administration of antireflux therapy placed all patients into remission; however, a break in therapy resulted in the return of papillomas, requiring debridement. ${ }^{137}$ Holland and colleagues ${ }^{138}$ showed a decrease in frequency of patients with RRP forming laryngeal webs when treated with antireflux medications. Unlike some of the previously mentioned adjuvant therapies, antireflux medications carry fewer adverse side effects and also provide added benefits to patients with vocal dysfunction from RRP disease. Further trials are needed to objectively evaluate and quantify the role of antireflux therapy in RRP, but the initial studies exploring concurrent treatment of LPRD seem to show an added benefit.

\section{SUMMARY ON RRP}

RRP is a benign disease of the upper aerodigestive tract caused by infection with HPV, and can have potentially life-threatening airway compromise and a protracted clinical course. The clinical course of this disease entity can be challenging for several reasons. In pediatric populations, the presenting symptoms are often nonspecific and subtle, which frequently results in a delayed diagnosis. Generally, the disease process is unpredictable, ranging from mild disease and spontaneous remission to an aggressive disease with pulmonary spread and requirements for frequent debulking procedures. In severe cases, the uncontrolled proliferation of papillomas can result in airway compromise and the need for an emergent airway. However, the procedure to establish an airway may lead to distal spread of the disease and additional surgeries. Because there is no known cure, multiple surgical debridements have become the mainstay of treatment. Advanced instrumentation, such as the microdebrider and newer angiolytic lasers (KTP, pulse-dyed laser), has allowed more precise removal and thus easier preservation of delicate laryngeal tissues, with improved 
voice results. Although considered rare, this disease entity is potentially devastating and costly to patients, families, and society in general, which highlights its clinical relevance.

Although studies of the molecular mechanisms and pathophysiology of low-risk HPVs are limited, this is an area primed for innovation. Major strides have been achieved in this field already with the development of the HPV vaccine, which shows promise for reducing the prevalence of RRP, in addition to eliminating cervical cancer. Advancing the basic science and clinical translational research made available from studying the high-risk HPV types carries the potential for new discoveries and novel therapies for RRP.

\section{References}

1. Tasca RA, Clarke RW. Recurrent respiratory papillomatosis. Arch Dis Child. 2006; 91(8):689-91. [PubMed: 16861486]

2. Derkay CS, Wiatrak B. Recurrent respiratory papillomatosis: a review. Laryngoscope. 2008; 118(7): 1236-47. [PubMed: 18496162]

3. Derkay CS. Task force on recurrent respiratory papillomas. A preliminary report. Arch Otolaryngol Head Neck Surg. 1995; 121(12):1386-91. [PubMed: 7488368]

4. Marsico, M.; Mehta, V.; Wentworth, C., et al. Estimating the disease burden of juvenile onset RRP in the US using large administrative databases - preliminary pilot results [abstract P-03.58]. Presented May 2009 at the International Papillomavirus Conference; Available at: http:// www.hpv2009.org

5. Leung R, Hawkes M, Campisi P. Severity of juvenile onset recurrent respiratory papillomatosis is not associated with socioeconomic status in a setting of universal health care. Int $\mathrm{J}$ Pediatr Otorhinolaryngol. 2007; 71(6):965-72. [PubMed: 17428551]

6. Armstrong LR, Derkay CS, Reeves WC. Initial results from the national registry for juvenile-onset recurrent respiratory papillomatosis. RRP Task Force. Arch Otolaryngol Head Neck Surg. 1999; 125(7):743-8. [PubMed: 10406310]

7. Larson DA, Derkay CS. Epidemiology of recurrent respiratory papillomatosis. APMIS. 2010; 118(6-7):450-4. [PubMed: 20553527]

8. Ullman EV. On the aetiology of laryngeal papilloma. Acta Otolaryngol. 1923; 5:317.

9. Gissmann L, Wolnik L, Ikenberg H, et al. Human papillomavirus types 6 and 11 DNA sequences in genital and laryngeal papillomas and in some cervical cancers. Proc Natl Acad Sci U S A. 1983; 80(2):560-3. [PubMed: 6300854]

10. Mounts P, Shah KV, Kashima H. Viral etiology of juvenile- and adult-onset squamous papilloma of the larynx. Proc Natl Acad Sci U S A. 1982; 79(17):5425-9. [PubMed: 6291043]

11. Gabbott M, Cossart YE, Kan A, et al. Human papillomavirus and host variables as predictors of clinical course in patients with juvenile-onset recurrent respiratory papillomatosis. J Clin Microbiol. 1997; 35(12):3098-103. [PubMed: 9399501]

12. Pou AM, Rimell FL, Jordan JA, et al. Adult respiratory papillomatosis: human papillomavirus type and viral coinfections as predictors of prognosis. Ann Otol Rhinol Laryngol. 1995; 104(10 Pt 1): 758-62. [PubMed: 7574251]

13. Duggan MA, Lim M, Gill MJ, et al. HPV DNA typing of adult-onset respiratory papillomatosis. Laryngoscope. 1990; 100(6):639-42. [PubMed: 2161484]

14. Major T, Szarka K, Sziklai I, et al. The characteristics of human papillomavirus DNA in head and neck cancers and papillomas. J Clin Pathol. 2005; 58(1):51-5. [PubMed: 15623482]

15. Derkay CS, Darrow DH. Recurrent respiratory papillomatosis. Ann Otol Rhinol Laryngol. 2006; 115(1):1-11. [PubMed: 16466093]

16. Hartley C, Hamilton J, Birzgalis AR, et al. Recurrent respiratory papillomatosis-the Manchester experience, 1974-1992. J Laryngol Otol. 1994; 108(3):226-9. [PubMed: 8169504]

17. Donne AJ, Hampson L, Homer JJ, et al. The role of HPV type in recurrent respiratory papillomatosis. Int J Pediatr Otorhinolaryngol. 2010; 74(1):7-14. [PubMed: 19800138] 
18. Gorgoulis V, Rassidakis G, Karameris A, et al. Expression of p53 protein in laryngeal squamous cell carcinoma and dysplasia: possible correlation with human papillomavirus infection and clinicopathological findings. Virchows Arch. 1994; 425(5):481-9. [PubMed: 7850072]

19. Majoros M, Devine KD, Parkhill EM. Malignant transformation of benign laryngeal papillomas in children after radiation therapy. Surg Clin North Am. 1963; 43:1049-61. [PubMed: 14049822]

20. Reidy PM, Dedo HH, Rabah R, et al. Integration of human papillomavirus type 11 in recurrent respiratory papilloma-associated cancer. Laryngoscope. 2004; 114(11):1906-9. [PubMed: 15510012]

21. Go C, Schwartz MR, Donovan DT. Molecular transformation of recurrent respiratory papillomatosis: viral typing and p53 overexpression. Ann Otol Rhinol Laryngol. 2003; 112(4): 298-302. [PubMed: 12731623]

22. Miller CS, Johnstone BM. Human papillomavirus as a risk factor for oral squamous cell carcinoma: a meta-analysis, 1982-1997. Oral Surg Oral Med Oral Pathol Oral Radiol Endod. 2001; 91(6):622-35. [PubMed: 11402272]

23. Smith EM, Pignatari SS, Gray SD, et al. Human papillomavirus infection in papillomas and nondiseased respiratory sites of patients with recurrent respiratory papillomatosis using the polymerase chain reaction. Arch Otolaryngol Head Neck Surg. 1993; 119(5):554-7. [PubMed: 8387317]

24. Stern Y, Felipovich A, Cotton RT, et al. Immunocompetency in children with recurrent respiratory papillomatosis: prospective study. Ann Otol Rhinol Laryngol. 2007; 116(3):169-71. [PubMed: 17419519]

25. Munger K, Phelps WC, Bubb V, et al. The E6 and E7 genes of the human papillomavirus type 16 together are necessary and sufficient for transformation of primary human keratinocytes. J Virol. 1989; 63(10):4417-21. [PubMed: 2476573]

26. Scheffner M, Werness BA, Huibregtse JM, et al. The E6 oncoprotein encoded by human papillomavirus types 16 and 18 promotes the degradation of p53. Cell. 1990; 63(6):1129-36. [PubMed: 2175676]

27. Li X, Coffino P. High-risk human papillomavirus E6 protein has two distinct binding sites within p53, of which only one determines degradation. J Virol. 1996; 70(7):4509-16. [PubMed: 8676476]

28. Pietsch EC, Murphy ME. Low risk HPV-E6 traps p53 in the cytoplasm and induces p53-dependent apoptosis. Cancer Biol Ther. 2008; 7(12):1916-8. [PubMed: 19158479]

29. Helt AM, Galloway DA. Mechanisms by which DNA tumor virus oncoproteins target the Rb family of pocket proteins. Carcinogenesis. 2003; 24(2):159-69. [PubMed: 12584163]

30. Barbosa MS, Vass WC, Lowy DR, et al. In vitro biological activities of the E6 and E7 genes vary among human papillomaviruses of different oncogenic potential. J Virol. 1991; 65(1):292-8. [PubMed: 1845889]

31. Abramson AL, Steinberg BM, Winkler B. Laryngeal papillomatosis: clinical, histopathologic and molecular studies. Laryngoscope. 1987; 97(6):678-85. [PubMed: 3035299]

32. Steinberg BM, Meade R, Kalinowski S, et al. Abnormal differentiation of human papillomavirusinduced laryngeal papillomas. Arch Otolaryngol Head Neck Surg. 1990; 116(10):1167-71.

[PubMed: 1698389]

33. Cogliano V, Baan R, Straif K, et al. Carcinogenicity of human papillomaviruses. Lancet Oncol. 2005; 6(4):204. [PubMed: 15830458]

34. zur Hausen H. Papillomaviruses in human cancers. Proc Assoc Am Physicians. 1999; 111(6):5817. [PubMed: 10591087]

35. Helt AM, Funk JO, Galloway DA. Inactivation of both the retinoblastoma tumor suppressor and p21 by the human papillomavirus type $16 \mathrm{E} 7$ oncoprotein is necessary to inhibit cell cycle arrest in human epithelial cells. J Virol. 2002; 76(20):10559-68. [PubMed: 12239337]

36. Longworth MS, Wilson R, Laimins LA. HPV31 E7 facilitates replication by activating E2F2 transcription through its interaction with HDACs. EMBO J. 2005; 24(10):1821-30. [PubMed: 15861133]

37. Demers GW, Halbert CL, Galloway DA. Elevated wild-type p53 protein levels in human epithelial cell lines immortalized by the human papillomavirus type 16 E7 gene. Virology. 1994; 198(1): 169-74. [PubMed: 8259651] 
38. Jones DL, Thompson DA, Munger K. Destabilization of the RB tumor suppressor protein and stabilization of p53 contribute to HPV type 16 E7-induced apoptosis. Virology. 1997; 239(1):97107. [PubMed: 9426450]

39. Seavey SE, Holubar M, Saucedo LJ, et al. The E7 oncoprotein of human papillomavirus type 16 stabilizes p53 through a mechanism independent of p19(ARF). J Virol. 1999; 73(9):7590-8. [PubMed: 10438849]

40. Bates S, Phillips AC, Clark PA, et al. p14ARF links the tumour suppressors RB and p53. Nature. 1998; 395(6698):124-5. [PubMed: 9744267]

41. Pietenpol JA, Stein RW, Moran E, et al. TGF-beta 1 inhibition of c-myc transcription and growth in keratinocytes is abrogated by viral transforming proteins with pRB binding domains. Cell. 1990; 61(5):777-85. [PubMed: 2140528]

42. Borger DR, Mi Y, Geslani G, et al. Retinoic acid resistance at late stages of human papillomavirus type 16-mediated transformation of human keratinocytes arises despite intact retinoid signaling and is due to a loss of sensitivity to transforming growth factor-beta. Virology. 2000; 270(2):397407. [PubMed: 10792999]

43. Munger K, Basile JR, Duensing S, et al. Biological activities and molecular targets of the human papillomavirus E7 oncoprotein. Oncogene. 2001; 20(54):7888-98. [PubMed: 11753671]

44. Barnard P, McMillan NA. The human papillomavirus E7 oncoprotein abrogates signaling mediated by interferon-alpha. Virology. 1999; 259(2):305-13. [PubMed: 10388655]

45. Park JS, Kim EJ, Kwon HJ, et al. Inactivation of interferon regulatory factor-1 tumor suppressor protein by HPV E7 oncoprotein. Implication for the E7-mediated immune evasion mechanism in cervical carcinogenesis. J Biol Chem. 2000; 275(10):6764-9. [PubMed: 10702232]

46. Brehm A, Nielsen SJ, Miska EA, et al. The E7 oncoprotein associates with Mi2 and histone deacetylase activity to promote cell growth. EMBO J. 1999; 18(9):2449-58. [PubMed: 10228159]

47. Luscher-Firzlaff JM, Westendorf JM, Zwicker J, et al. Interaction of the fork head domain transcription factor MPP2 with the human papilloma virus $16 \mathrm{E} 7$ protein: enhancement of transformation and transactivation. Oncogene. 1999; 18(41):5620-30. [PubMed: 10523841]

48. Mannhardt B, Weinzimer SA, Wagner M, et al. Human papillomavirus type 16 E7 oncoprotein binds and inactivates growth-inhibitory insulin-like growth factor binding protein 3. Mol Cell Biol. 2000; 20(17):6483-95. [PubMed: 10938125]

49. Patel D, Huang SM, Baglia LA, et al. The E6 protein of human papillomavirus type 16 binds to and inhibits co-activation by CBP and p300. EMBO J. 1999; 18(18):5061-72. [PubMed: 10487758]

50. Jackson S, Harwood C, Thomas M, et al. Role of Bak in UV-induced apoptosis in skin cancer and abrogation by HPV E6 proteins. Genes Dev. 2000; 14(23):3065-73. [PubMed: 11114894]

51. Thomas M, Pim D, Banks L. The role of the E6-p53 interaction in the molecular pathogenesis of HPV. Oncogene. 1999; 18(53):7690-700. [PubMed: 10618709]

52. Filippova M, Parkhurst L, Duerksen-Hughes PJ. The human papillomavirus 16 E6 protein binds to Fas-associated death domain and protects cells from Fas-triggered apoptosis. J Biol Chem. 2004; 279(24):25729-44. [PubMed: 15073179]

53. Finzer P, Aguilar-Lemarroy A, Rosl F. The role of human papillomavirus oncoproteins E6 and E7 in apoptosis. Cancer Lett. 2002; 188(1-2):15-24. [PubMed: 12406543]

54. Giampieri S, Storey A. Repair of UV-induced thymine dimers is compromised in cells expressing the E6 protein from human papillomaviruses types 5 and 18. Br J Cancer. 2004; 90(11):2203-9. [PubMed: 15150558]

55. Thomas M, Banks L. Human papillomavirus (HPV) E6 interactions with Bak are conserved amongst E6 proteins from high and low risk HPV types. J Gen Virol. 1999; 80(Pt 6):1513-7. [PubMed: 10374970]

56. Jackson S, Storey A. E6 proteins from diverse cutaneous HPV types inhibit apoptosis in response to UV damage. Oncogene. 2000; 19(4):592-8. [PubMed: 10698529]

57. Giampieri S, Garcia-Escudero R, Green J, et al. Human papillomavirus type 77 E6 protein selectively inhibits p53-dependent transcription of proapoptotic genes following UV-B irradiation. Oncogene. 2004; 23(34):5864-70. [PubMed: 15077176] 
58. Accardi R, Dong W, Smet A, et al. Skin human papillomavirus type 38 alters p53 functions by accumulation of deltaNp73. EMBO Rep. 2006; 7(3):334-40. [PubMed: 16397624]

59. Klingelhutz AJ, Foster SA, McDougall JK. Telomerase activation by the E6 gene product of human papillomavirus type 16. Nature. 1996; 380(6569):79-82. [PubMed: 8598912]

60. Gewin L, Myers H, Kiyono T, et al. Identification of a novel telomerase repressor that interacts with the human papillomavirus type-16 E6/E6-AP complex. Genes Dev. 2004; 18(18):2269-82. [PubMed: 15371341]

61. Storey A, Osborn K, Crawford L. Co-transformation by human papillomavirus types 6 and 11. J Gen Virol. 1990; 71(Pt 1):165-71. [PubMed: 2154533]

62. Storey A, Pim D, Murray A, et al. Comparison of the in vitro transforming activities of human papillomavirus types. EMBO J. 1988; 7(6):1815-20. [PubMed: 2458921]

63. Demers GW, Foster SA, Halbert CL, et al. Growth arrest by induction of p53 in DNA damaged keratinocytes is bypassed by human papillomavirus 16 E7. Proc Natl Acad Sci U S A. 1994; 91(10):4382-6. [PubMed: 8183918]

64. Nomine Y, Masson M, Charbonnier S, et al. Structural and functional analysis of E6 oncoprotein: insights in the molecular pathways of human papillomavirus-mediated pathogenesis. Mol Cell. 2006; 21(5):665-78. [PubMed: 16507364]

65. Gage JR, Meyers C, Wettstein FO. The E7 proteins of the nononcogenic human papillomavirus type $6 \mathrm{~b}(\mathrm{HPV}-6 \mathrm{~b})$ and of the oncogenic HPV-16 differ in retinoblastoma protein binding and other properties. J Virol. 1990; 64(2):723-30. [PubMed: 2153238]

66. Gupta S, Takhar PP, Degenkolbe R, et al. The human papillomavirus type 11 and 16 E6 proteins modulate the cell-cycle regulator and transcription cofactor TRIP-Br1. Virology. 2003; 317(1): 155-64. [PubMed: 14675634]

67. Jha S, Vande PS, Banerjee NS, et al. Destabilization of TIP60 by human papillomavirus E6 results in attenuation of TIP60-dependent transcriptional regulation and apoptotic pathway. Mol Cell. 2010; 38(5):700-11. [PubMed: 20542002]

68. Park JS, Kim EJ, Lee JY, et al. Functional inactivation of p73, a homolog of p53 tumor suppressor protein, by human papillomavirus E6 proteins. Int J Cancer. 2001; 91(6):822-7. [PubMed: 11275986]

69. Underbrink MP, Howie HL, Bedard KM, et al. E6 proteins from multiple human betapapillomavirus types degrade Bak and protect keratinocytes from apoptosis after UVB irradiation. J Virol. 2008; 82(21):10408-17. [PubMed: 18715924]

70. Avvakumov N, Torchia J, Mymryk JS. Interaction of the HPV E7 proteins with the pCAF acetyltransferase. Oncogene. 2003; 22(25):3833-41. [PubMed: 12813456]

71. Bernat A, Avvakumov N, Mymryk JS, et al. Interaction between the HPV E7 oncoprotein and the transcriptional coactivator p300. Oncogene. 2003; 22(39):7871-81. [PubMed: 12970734]

72. Cheng S, Schmidt-Grimminger DC, Murant T, et al. Differentiation-dependent up-regulation of the human papillomavirus E7 gene reactivates cellular DNA replication in suprabasal differentiated keratinocytes. Genes Dev. 1995; 9(19):2335-49. [PubMed: 7557386]

73. Zhang B, Chen W, Roman A. The E7 proteins of low- and high-risk human papillomaviruses share the ability to target the pRB family member p130 for degradation. Proc Natl Acad Sci U S A. 2006; 103(2):437-42. [PubMed: 16381817]

74. Bonagura VR, Hatam L, DeVoti J, et al. Recurrent respiratory papillomatosis: altered CD8(+) Tcell subsets and $\mathrm{T}(\mathrm{H}) 1 / \mathrm{T}(\mathrm{H}) 2$ cytokine imbalance. Clin Immunol. 1999; 93(3):302-11. [PubMed: 10600342]

75. DeVoti JA, Rosenthal DW, Wu R, et al. Immune dysregulation and tumor-associated gene changes in recurrent respiratory papillomatosis: a paired microarray analysis. Mol Med. 2008; 14(9-10): 608-17. [PubMed: 18607510]

76. DeVoti JA, Steinberg BM, Rosenthal DW, et al. Failure of gamma interferon but not interleukin-10 expression in response to human papillomavirus type 11 E6 protein in respiratory papillomatosis. Clin Diagn Lab Immunol. 2004; 11(3):538-47.

77. Vambutas A, Bonagura VR, Steinberg BM. Altered expression of TAP-1 and major histocompatibility complex class I in laryngeal papillomatosis: correlation of TAP-1 with disease. Clin Diagn Lab Immunol. 2000; 7(1):79-85. [PubMed: 10618282] 
78. Weinstock H, Berman S, Cates W Jr. Sexually transmitted diseases among American youth: incidence and prevalence estimates, 2000. Perspect Sex Reprod Health. 2004; 36(1):6-10. [PubMed: 14982671]

79. Dunne EF, Unger ER, Sternberg M, et al. Prevalence of HPV infection among females in the United States. JAMA. 2007; 297(8):813-9. [PubMed: 17327523]

80. Manhart LE, Holmes KK, Koutsky LA, et al. Human papillomavirus infection among sexually active young women in the United States: implications for developing a vaccination strategy. Sex Transm Dis. 2006; 33(8):502-8. [PubMed: 16572039]

81. Silverberg MJ, Thorsen $\mathrm{P}$, Lindeberg $\mathrm{H}$, et al. Condyloma in pregnancy is strongly predictive of juvenile-onset recurrent respiratory papillomatosis. Obstet Gynecol. 2003; 101(4):645-52. [PubMed: 12681865]

82. Kashima HK, Shah F, Lyles A, et al. A comparison of risk factors in juvenile-onset and adult-onset recurrent respiratory papillomatosis. Laryngoscope. 1992; 102(1):9-13. [PubMed: 1309932]

83. Shah KV, Stern WF, Shah FK, et al. Risk factors for juvenile onset recurrent respiratory papillomatosis. Pediatr Infect Dis J. 1998; 17(5):372-6. [PubMed: 9613648]

84. Rombaldi RL, Serafini EP, Mandelli J, et al. Transplacental transmission of human papillomavirus. Virol J. 2008; 5:106. [PubMed: 18817577]

85. Winckworth LC, Nichol R. Question 2: do caesarean sections reduce the maternal-fetal transmission rate of human papillomavirus infection? Arch Dis Child. 2010; 95(1):70-3.

86. Puranen MH, Yliskoski MH, Saarikoski SV, et al. Exposure of an infant to cervical human papillomavirus infection of the mother is common. Am J Obstet Gynecol. 1997; 176(5):1039-45.

87. Bandyopadhyay S, Sen S, Majumdar L, et al. Human papillomavirus infection among Indian mothers and their infants. Asian Pac J Cancer Prev. 2003; 4(3):179-84.

88. Smith EM, Ritchie JM, Yankowitz J, et al. Human papillomavirus prevalence and types in newborns and parents: concordance and modes of transmission. Sex Transm Dis. 2004; 31(1):5762. [PubMed: 14695959]

89. Wang X, Zhu Q, Rao H. Maternal-fetal transmission of human papillomavirus. Chin Med J (Engl). 1998; 111(8):726-7. [PubMed: 11245028]

90. Tseng CJ, Liang CC, Soong YK, et al. Perinatal transmission of human papillomavirus in infants: relationship between infection rate and mode of delivery. Obstet Gynecol. 1998; 91(1):92-6. [PubMed: 9464728]

91. Tenti P, Zappatore R, Migliora P, et al. Perinatal transmission of human papillomavirus from gravidas with latent infections. Obstet Gynecol. 1999; 93(4):475-9. [PubMed: 10214817]

92. Villa LL, Costa RL, Petta CA, et al. Prophylactic quadrivalent human papillomavirus (types 6, 11, 16, and 18) L1 virus-like particle vaccine in young women: a randomised double-blind placebocontrolled multicentre phase II efficacy trial. Lancet Oncol. 2005; 6(5):271-8. [PubMed: 15863374]

93. Markowitz LE, Dunne EF, Saraiya M, et al. Quadrivalent human papillomavirus vaccine: recommendations of the Advisory Committee on Immunization Practices (ACIP). MMWR Recomm Rep. 2007; 56(RR-2):1-24. [PubMed: 17380109]

94. Dallard C. Legislating against arousal: the growing divide between federal policy and teenage sexual behavior. Gutmacher Policy Rev. 2006; 9:12-6.

95. May J. HPV vaccination - a paradigm shift in public health. Aust Fam Physician. 2007; 36(3):10611. [PubMed: 17339969]

96. Gallagher TQ, Derkay CS. Recurrent respiratory papillomatosis: update 2008. Curr Opin Otolaryngol Head Neck Surg. 2008; 16(6):536-42. [PubMed: 19005325]

97. Schaffer A, Brotherton J, Booy R. Do human papillomavirus vaccines have any role in newborns and the prevention of recurrent respiratory papillomatosis in children? J Paediatr Child Health. 2007; 43(9):579-80. [PubMed: 17688640]

98. Kashima H, Mounts P, Leventhal B, et al. Sites of predilection in recurrent respiratory papillomatosis. Ann Otol Rhinol Laryngol. 1993; 102(8 Pt 1):580-3. [PubMed: 8394667]

99. Silverberg MJ, Thorsen P, Lindeberg H, et al. Clinical course of recurrent respiratory papillomatosis in Danish children. Arch Otolaryngol Head Neck Surg. 2004; 130(6):711-6. [PubMed: 15210551] 
100. Wetmore, RF.; Muntz, HR.; McGill, TJI. Pediatric otolaryngology: principles and practice pathways. New York: Thieme; 2000.

101. Cohn AM, Kos JT, Taber LH, et al. Recurring laryngeal papilloma. Am J Otolaryngol. 1981; 2(2):129-32. [PubMed: 7196701]

102. Schraff S, Derkay CS, Burke B, et al. American Society of Pediatric Otolaryngology members' experience with recurrent respiratory papillomatosis and the use of adjuvant therapy. Arch Otolaryngol Head Neck Surg. 2004; 130(9):1039-42. [PubMed: 15381589]

103. Xue Q, Wang J. Recurrent respiratory papillomatosis arising in trachea not affecting larynx. Intern Med. 2010; 49(15):1649-51. [PubMed: 20686308]

104. Katsenos S, Becker HD. Recurrent respiratory papillomatosis: a rare chronic disease, difficult to treat, with potential to lung cancer transformation: apropos of two cases and a brief literature review. Case Rep Oncol. 2011; 4(1):162-71. [PubMed: 21526134]

105. Cook JR, Hill DA, Humphrey PA, et al. Squamous cell carcinoma arising in recurrent respiratory papillomatosis with pulmonary involvement: emerging common pattern of clinical features and human papillomavirus serotype association. Mod Pathol. 2000; 13(8):914-8. [PubMed: 10955460]

106. Derkay CS, Malis DJ, Zalzal G, et al. A staging system for assessing severity of disease and response to therapy in recurrent respiratory papillomatosis. Laryngoscope. 1998; 108(6):935-7. [PubMed: 9628513]

107. Derkay CS, Hester RP, Burke B, et al. Analysis of a staging assessment system for prediction of surgical interval in recurrent respiratory papillomatosis. Int J Pediatr Otorhinolaryngol. 2004; 68(12):1493-8. [PubMed: 15533560]

108. Cole RR, Myer CM III, Cotton RT. Tracheotomy in children with recurrent respiratory papillomatosis. Head Neck. 1989; 11(3):226-30. [PubMed: 2722498]

109. Healy GB, Gelber RD, Trowbridge AL, et al. Treatment of recurrent respiratory papillomatosis with human leukocyte interferon. Results of a multicenter randomized clinical trial. N Engl J Med. 1988; 319(7):401-7. [PubMed: 3398891]

110. Leventhal BG, Kashima HK, Mounts P, et al. Long-term response of recurrent respiratory papillomatosis to treatment with lymphoblastoid interferon alfa-N1. Papilloma Study Group. N Engl J Med. 1991; 325(9):613-7. [PubMed: 1861694]

111. Gerein V, Rastorguev E, Gerein J, et al. Use of interferon-alpha in recurrent respiratory papillomatosis: 20-year follow-up. Ann Otol Rhinol Laryngol. 2005; 114(6):463-71.

112. Morrison GA, Kotecha B, Evans JN. Ribavirin treatment for juvenile respiratory papillomatosis. J Laryngol Otol. 1993; 107(5):423-6. [PubMed: 8326222]

113. Shehab N, Sweet BV, Hogikyan ND. Cidofovir for the treatment of recurrent respiratory papillomatosis: a review of the literature. Pharmacotherapy. 2005; 25(7):977-89. [PubMed: 16006276]

114. Ksiazek J, Prager JD, Sun GH, et al. Inhaled cidofovir as an adjuvant therapy for recurrent respiratory papillomatosis. Otolaryngol Head Neck Surg. 2011; 144(4):639-41. [PubMed: 21493248]

115. Pransky SM, Albright JT, Magit AE. Long-term follow-up of pediatric recurrent respiratory papillomatosis managed with intralesional cidofovir. Laryngoscope. 2003; 113(9):1583-7. [PubMed: 12972938]

116. Milczuk HA. Intralesional cidofovir for the treatment of severe juvenile recurrent respiratory papillomatosis: long-term results in 4 children. Otolaryngol Head Neck Surg. 2003; 128(6):78894. [PubMed: 12825028]

117. Akst LM, Lee W, Discolo C, et al. Stepped-dose protocol of cidofovir therapy in recurrent respiratory papillomatosis in children. Arch Otolaryngol Head Neck Surg. 2003; 129(8):841-6. [PubMed: 12925342]

118. Lee AS, Rosen CA. Efficacy of cidofovir injection for the treatment of recurrent respiratory papillomatosis. J Voice. 2004; 18(4):551-6. [PubMed: 15567056]

119. Peyton SW, Wiatrak B. Is cidofovir a useful adjunctive therapy for recurrent respiratory papillomatosis in children? Int J Pediatr Otorhinolaryngol. 2004; 68(4):413-8. 
120. Mandell DL, Arjmand EM, Kay DJ, et al. Intralesional cidofovir for pediatric recurrent respiratory papillomatosis. Arch Otolaryngol Head Neck Surg. 2004; 130(11):1319-23. [PubMed: 15545589]

121. Naiman AN, Ceruse P, Coulombeau B, et al. Intralesional cidofovir and surgical excision for laryngeal papillomatosis. Laryngoscope. 2003; 113(12):2174-81. [PubMed: 14660923]

122. Goon P, Sonnex C, Jani P, et al. Recurrent respiratory papillomatosis: an overview of current thinking and treatment. Eur Arch Otorhinolaryngol. 2008; 265(2):147-51. [PubMed: 18046565]

123. Wutzler P, Thust R. Genetic risks of antiviral nucleoside analogues-a survey. Antiviral Res. 2001; 49(2):55-74. [PubMed: 11248359]

124. Chadha NK, James AL. Antiviral agents for the treatment of recurrent respiratory papillomatosis: a systematic review of the English-language literature. Otolaryngol Head Neck Surg. 2007; 136(6):863-9. [PubMed: 17547971]

125. Rosen CA, Bryson PC. Indole-3-carbinol for recurrent respiratory papillomatosis: long-term results. J Voice. 2004; 18(2):248-53. [PubMed: 15193659]

126. Derkay CS, Smith RJ, McClay J, et al. HspE7 treatment of pediatric recurrent respiratory papillomatosis: final results of an open-label trial. Ann Otol Rhinol Laryngol. 2005; 114(9):730 7. [PubMed: 16240938]

127. Pashley NR. Can mumps vaccine induce remission in recurrent respiratory papilloma? Arch Otolaryngol Head Neck Surg. 2002; 128(7):783-6. [PubMed: 12117334]

128. Lieu JE, Molter DW. Another potential adjuvant therapy for recurrent respiratory papillomatosis. Arch Otolaryngol Head Neck Surg. 2002; 128(7):787-8. [PubMed: 12117335]

129. Dolmans DE, Fukumura D, Jain RK. Photodynamic therapy for cancer. Nat Rev Cancer. 2003; 3(5):380-7. [PubMed: 12724736]

130. Dougherty TJ, Gomer CJ, Henderson BW, et al. Photodynamic therapy. J Natl Cancer Inst. 1998; 90(12):889-905. [PubMed: 9637138]

131. Shikowitz MJ, Abramson AL, Steinberg BM, et al. Clinical trial of photodynamic therapy with mesotetra (hydroxyphenyl) chlorin for respiratory papillomatosis. Arch Otolaryngol Head Neck Surg. 2005; 131(2):99-105. [PubMed: 15723939]

132. Lee RG, Vecchiotti MA, Heaphy J, et al. Photodynamic therapy of cottontail rabbit papillomavirus-induced papillomas in a severe combined immunodeficient mouse xenograft system. Laryngoscope. 2010; 120(3):618-24. [PubMed: 20091778]

133. Abramson AL, Shikowitz MJ, Mullooly VM, et al. Clinical effects of photodynamic therapy on recurrent laryngeal papillomas. Arch Otolaryngol Head Neck Surg. 1992; 118(1):25-9. [PubMed: 1309420]

134. Abramson AL, Shikowitz MJ, Mullooly VM, et al. Variable light-dose effect on photodynamic therapy for laryngeal papillomas. Arch Otolaryngol Head Neck Surg. 1994; 120(8):852-5. [PubMed: 8049048]

135. Borkowski G, Sommer P, Stark T, et al. Recurrent respiratory papillomatosis associated with gastroesophageal reflux disease in children. Eur Arch Otorhinolaryngol. 1999; 256(7):370-2. [PubMed: 10473833]

136. Harcourt JP, Worley G, Leighton SE. Cimetidine treatment for recurrent respiratory papillomatosis. Int J Pediatr Otorhinolaryngol. 1999; 51(2):109-13. [PubMed: 10619624]

137. McKenna M, Brodsky L. Extraesophageal acid reflux and recurrent respiratory papilloma in children. Int J Pediatr Otorhinolaryngol. 2005; 69(5):597-605. [PubMed: 15850681]

138. Holland BW, Koufman JA, Postma GN, et al. Laryngopharyngeal reflux and laryngeal web formation in patients with pediatric recurrent respiratory papillomas. Laryngoscope. 2002; 112(11):1926-9. [PubMed: 12439156] 


\section{KEY POINTS}

- Recurrent respiratory papillomatosis (RRP) is a rare, benign disease with no known cure, affecting millions of children; incidence is increased with lower socioeconomic status.

- $\quad$ RRP is caused by infection of the upper aerodigestive tract with the human papillomavirus (HPV). More than 100 types of HPV have been identified; the low-risk HPV types 6 and 11 are responsible for RRP.

- Transmission of RRP typically occurs from mother to neonate. Passage through the birth canal is thought to be the initial transmission event, but infection may occur in utero.

- HPV vaccines have helped to provide protection from cervical cancer; however, their role in the prevention of RRP is undetermined.

- Clinical presentation of initial symptoms of RRP may be subtle, including hoarseness, dyspnea, chronic cough, or recurrent upper respiratory infections.

- RRP course ranges from aggressive with pulmonary involvement to isolated laryngeal disease with spontaneous remission.

- Current management focuses on surgical debulking of papillomatous lesions with or without concurrent adjuvant therapy.

- Common adjuvant therapies used currently include cidofovir and interferon (IFN). 


\section{Note to the pediatrician: diagnosis of RRP}

Because of the location of RRP, definitive diagnosis requires direct visualization of the upper airway. Although this ultimately requires otolaryngology referral, the primary care provider can play a significant role in early diagnosis. As discussed earlier, RRP can present with a multitude of symptoms, including hoarseness, chronic cough, dyspnea, recurrent upper respiratory infections, pneumonias, dysphagia, stridor, or failure to thrive. Because of the often subtle nature of initial symptoms, many diseases, some of which may be more acute or emergent, are often considered first. When a patient does not show timely improvement with appropriate therapy for these initial diagnoses, RRP should be considered as an alternate diagnosis. In this capacity, the primary care provider plays an essential role in the process by having a high index of suspicion, which leads to an earlier diagnosis and implementation of a treatment plan. 


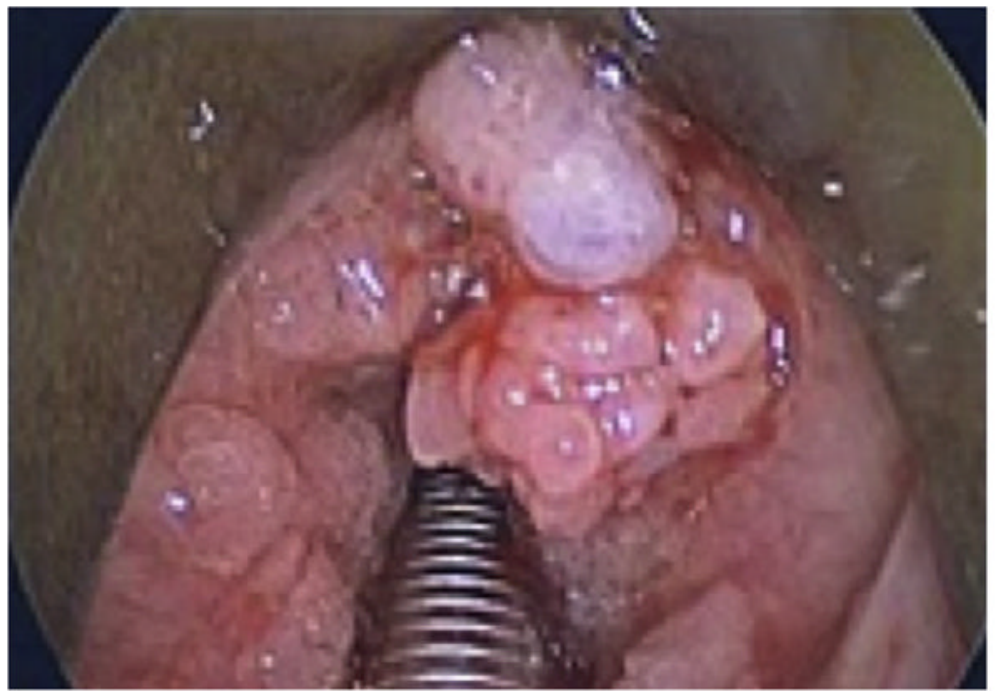

Fig. 1.

Various presentations of RRP. 


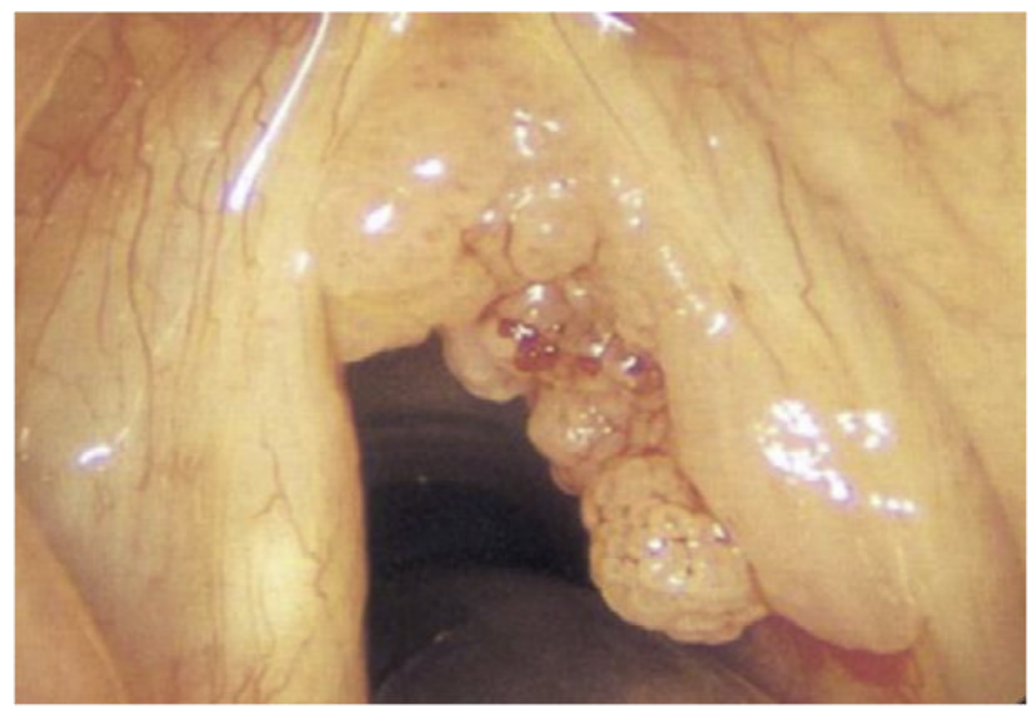

Fig. 2.

Various presentations of RRP. 


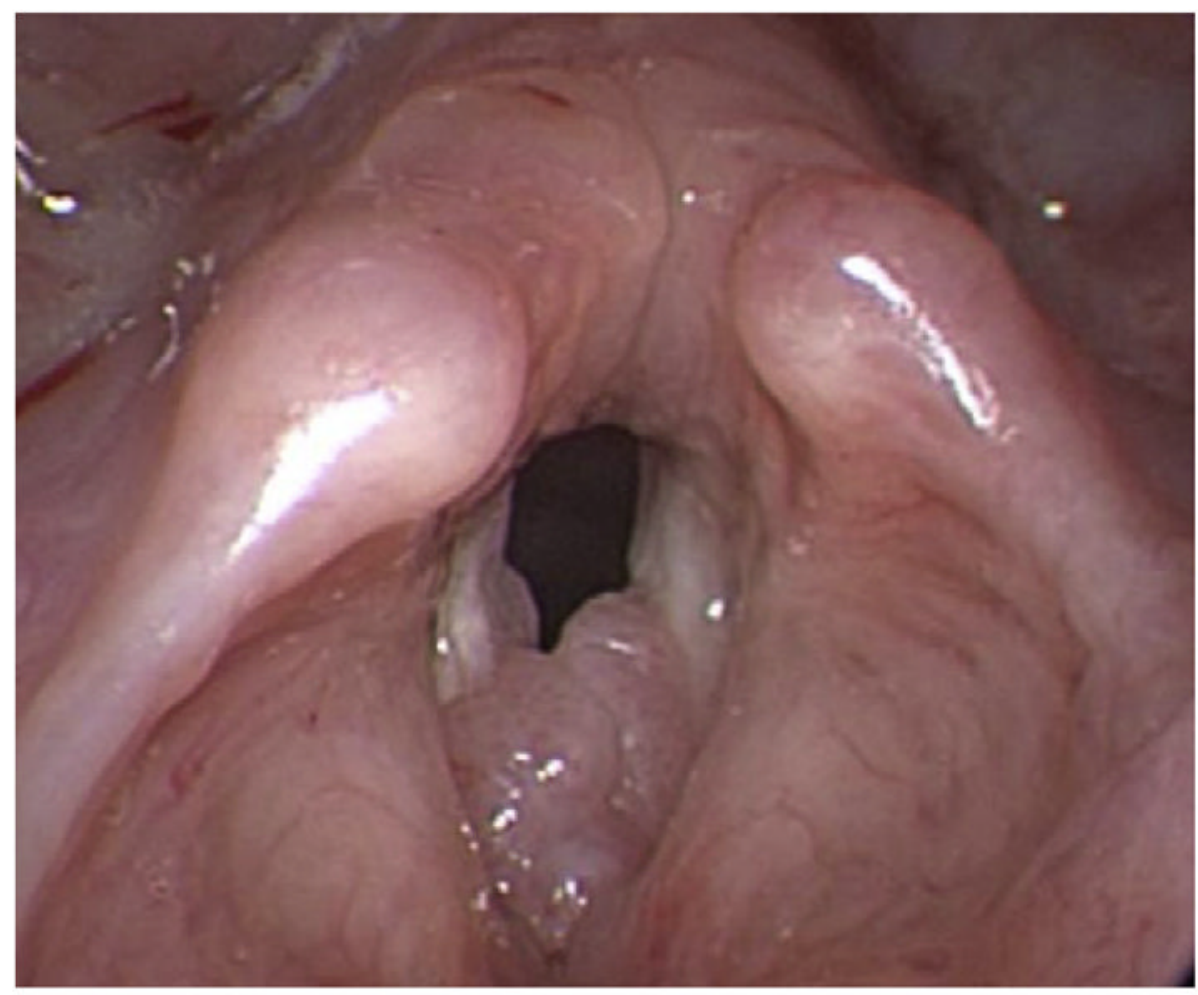

Fig. 3.

Various presentations of RRP. 


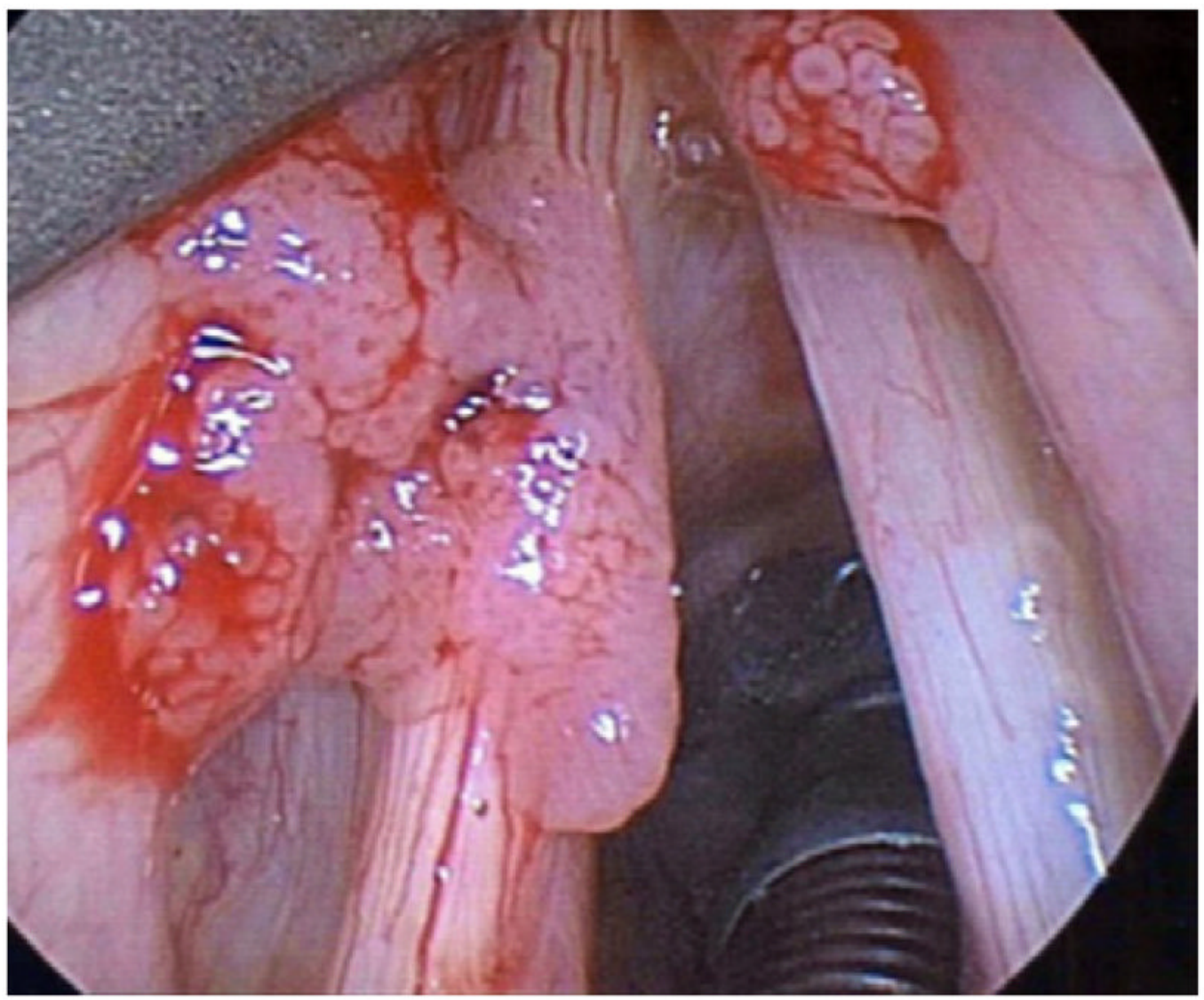

Fig. 4.

Various presentations of RRP. 


\section{STAGING ASSESSMENT FOR RECURRENT LARYNGEAL PAPILOMATOSIS}

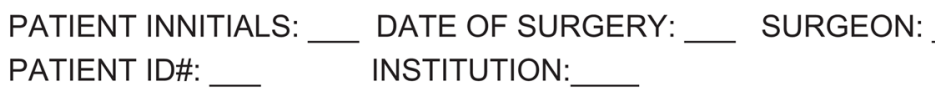

1. How long since the last papilloma surgery?

days,

weeks, months, years,

_don't know, __ 1st surgery

2. Counting today's surgery, how many papilloma surgeries in the past 12 months?

3. Describe the patient's voice today: normal (0), abnormal (1), aphonic (2)

4. Describe the patient's stridor today: absent (0), present with activity (1), present at rest (2)

5. Describe the urgency of today's intervention: emergent (3)

6. Describe today's level of respiratory distress: severe (3), extreme (4)

TOTAL SCORE for questions 3-6:

FOR EACH SITE, SCORE AS: 0 = none, 1 = surface lesion, 2 = raised lesion, 3 = bulky lesion

\section{LARYNX}

Epiglottis

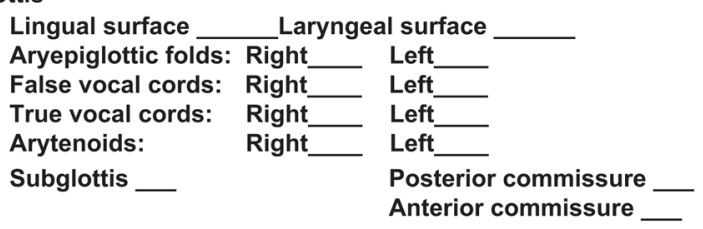

TRACHEA:

Upper one-third

Middle one-third

Lower one-third

Bronchi: Right __ Left

Trachcotomy stoma

OTHER

Nose

Palate

Pharynx

Lungs

Other

TOTAL SCORE ALL SITES:

Fig. 5.

Coltrera-Derkay staging and severity scheme.

(From Derkay CS, Malis DJ, Zalzal G, et al. A staging system for assessing severity of disease and response to therapy in recurrent respiratory papillomatosis. Laryngoscope 1998;108:936; with permission.) 


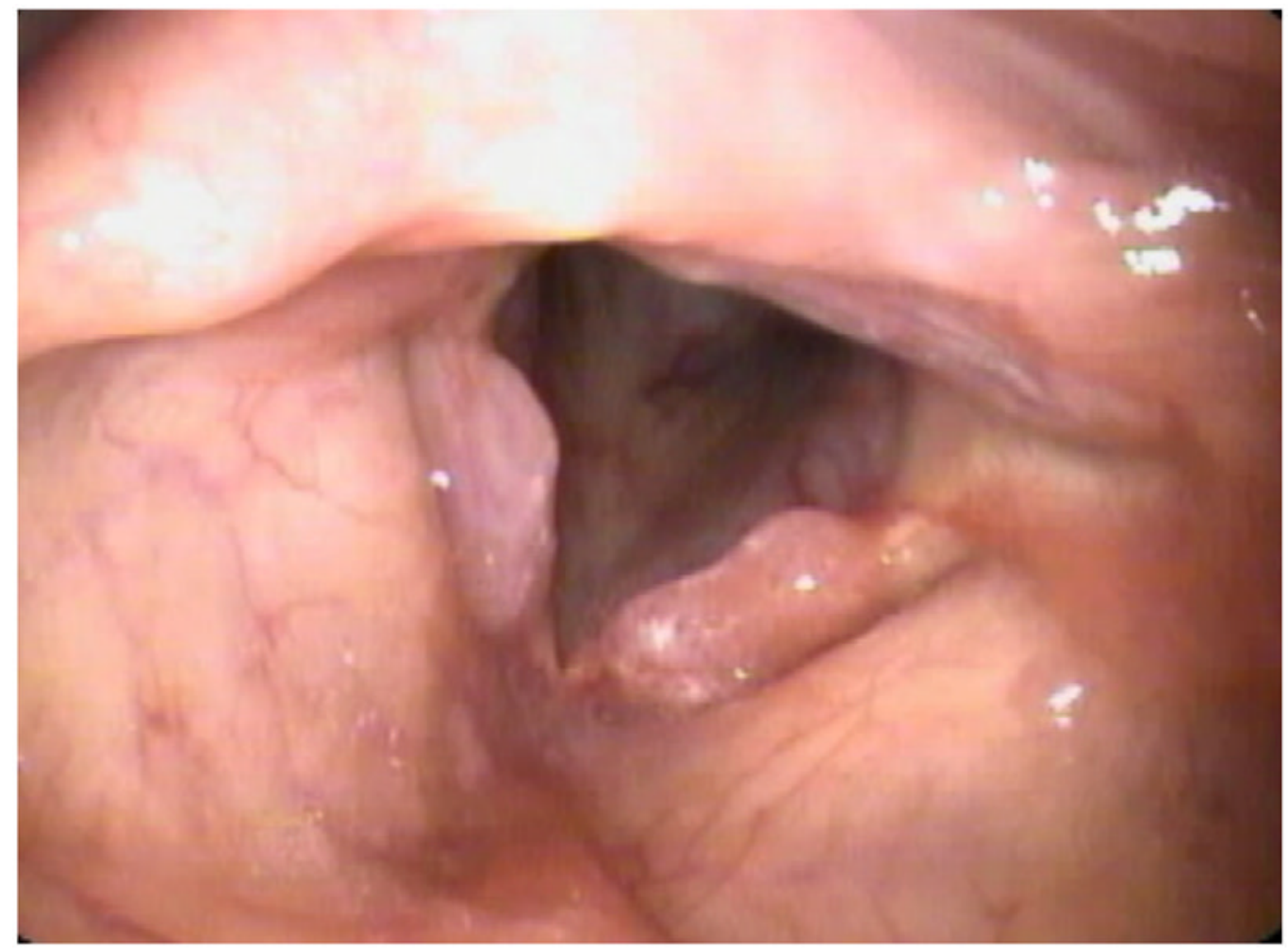

Fig. 6.

Pre-treatment initial presentation of laryngeal papillomas in a 37 year-old female patient. 


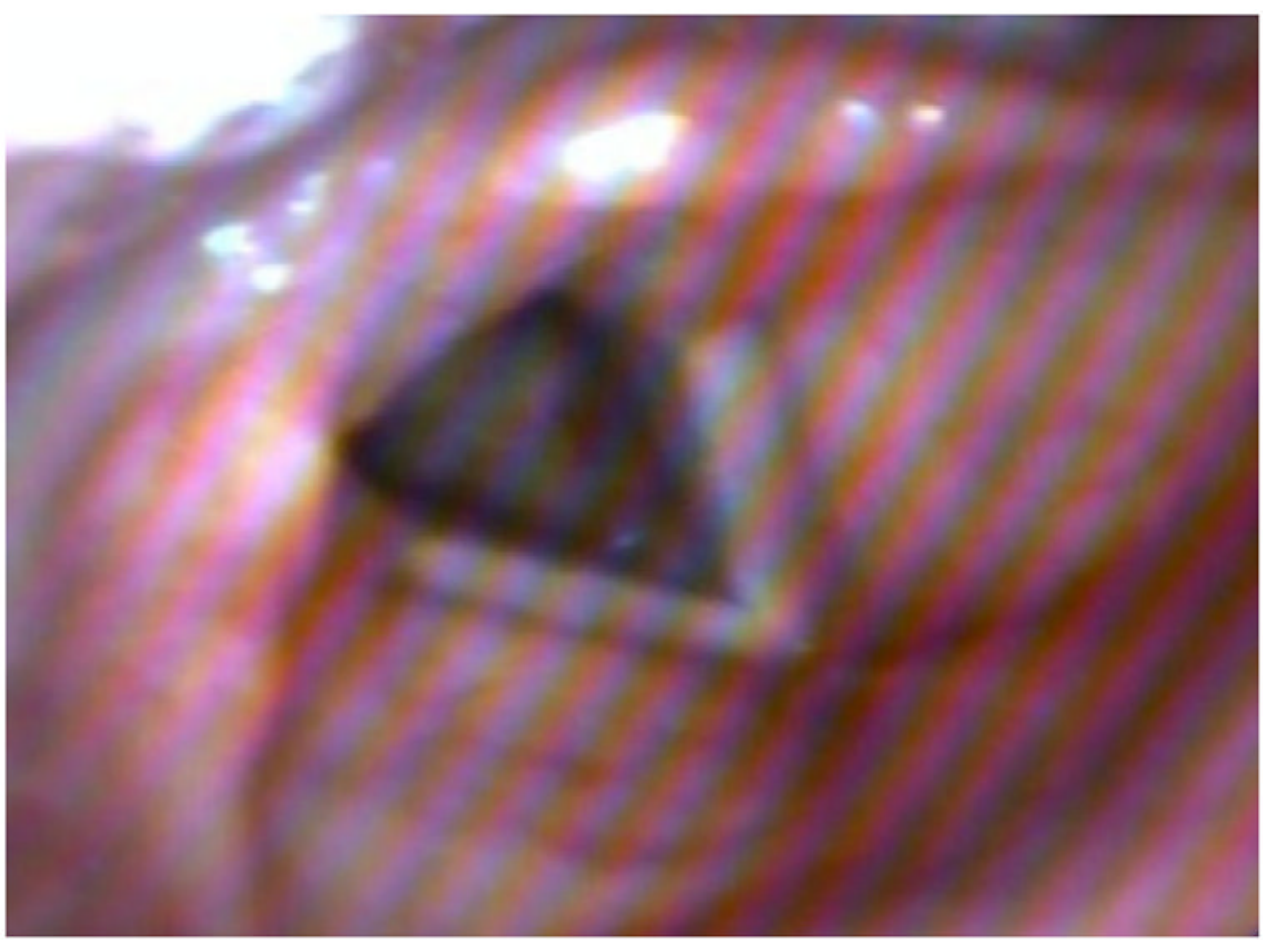

Fig. 7.

3 month post-treatment photo of 37 year old patient with new onset laryngeal papillomas (seen in Fig. 6). Treatment included microsurgical debridement of papillomas and aggressive anti-reflux therapy with twice daily proton pump inhibitors. 